\title{
Potensi Hiperakumulasi Saccharum spontaneum pada Medium Limbah Tailing Terkontaminasi Sianida
}

\author{
Hyperaccumulation Potency of Saccharum spontaneum in Tailing Waste Media \\ Contaminated by Cyanide
}

\author{
Nuril Hidayati*, Titi Juhaeti, Fauzia Syarif \\ Pusat Penelitian Biologi LIPI, Cibinong Science Center, Cibinong, Bogor \\ E-mail:criancht@yahoo.co.id *Penulis untuk korespondensi
}

\begin{abstract}
One approach to minimize risks from some toxic pollutants is phytoextraction using hyperaccumulator plants. These remarkable plant species accumulate appreciable high concentration of pollutants, including cyanide than normal plants. Although cyanide is not categorized as heavy metal, its presence is considered as one of important toxic pollutants in the environment. Detoxification of cyanide contaminated soils and waters with plants seems to be a feasible option. Since plants vary in their ability to accumulate specific contaminants, it is necessary to select plant species that can both accumulate and tolerate the contaminants. This study aims to characterized plants that grow under extreme contaminated media of gold mined tailing belongs to PT ANTAM Cikotok and to analyse their potencies as hyperaccumulators. Saccharum spontaneum which was proven tolerant and dominant in the contaminated site as well as potential in producing high biomass was used in this research. The plants were grown in tailing waste media added by 0,5 and $10 \mathrm{mg} \mathrm{kg}^{-1} \mathrm{CN}$. Organic fertilizers i.e. manure and compost were applied to increase $\mathrm{CN}$ uptake. The results showed that the plants were capable of growing under the highest level of CN. Application of organic fertilizer increased plant uptake. The results indicated that Saccharum spontaneum can be considered as high tolerance and potentially effective in accumulating $\mathrm{CN}$ in their roots and above ground portions.
\end{abstract}

Key words: hyperaccumulator, phytoextraction, cyanide, Saccharum spontaneum

Diterima: 01 Oktober 2007, disetujui: 10 Desember 2007

\section{Pendahuluan}

Sejumlah tumbuhan terbukti dapat beradaptasi terhadap lingkungan yang ekstrim seperti limbah pengolahan emas yang terkontaminasi logam berat dan sianida $(\mathrm{CN})$. Di antara tumbuhan ini banyak yang memiliki toleransi tinggi hingga mampu menyerap dan mengakumulasi logam kontaminan di dalam jaringannya. Kemampuan ini terbukti sangat penting untuk dimanfaatkan sebagai mediator pembersih tanah dan perairan yang tercemar (Hidayati et al., 2006b).
Walaupun CN bukan termasuk logam berat tetapi unsur ini termasuk pencemar penting pada lingkungan dan dapat menimbulkan bahaya keracunan. Di lingkungan penambangan emas, CN termasuk pencemar penting karena digunakan sebagai bahan utama dalam proses pengolahan emas sehingga limbah yang terbuang banyak mengandung $\mathrm{CN}$ dan dapat menyebar ke lingkungan di sekitarnya melalui aliran air dan mahluk hidup di dalamnya. Limbah tailing PT ANTAM Pongkor didapati mengandung $\mathrm{CN}$ hingga 0,77 $\mathrm{mg} \mathrm{kg}{ }^{-1}$, air sungai mengandung $0,14 \mathrm{mg} \mathrm{l}^{-1}$ dan sedimen sungai mengandung $0,72 \mathrm{mg} \mathrm{kg}^{-1} \mathrm{CN}$. 
Limbah tailing PT ANTAM Cikotok didapati mengandung 0,12 $\mathrm{mg} \mathrm{kg}^{-1} \mathrm{CN}$ (Hidayati et al., 2006b). Pencemaran ini tidak menutup kemungkinan untuk menyebar ke lingkungan pemukiman dan mencemari air tanah yang digunakan oleh masyarakat. Sementara ambang batas bahaya kandungan $\mathrm{CN}$ pada air minum hanya 0,005 $\mathrm{mg} \mathrm{l}^{-1}$ (Danish, 1995 dalam Larsen, 2005).

Di alam, sianida diproduksi dalam jaringan tanaman sendiri sebagai produk samping dari proses sintesis etilen, yang terjadi terutama pada saat ada jaringan tanaman terluka, perkecambahan, penuaan daun, dan pemasakan buah. Karena $\mathrm{CN}$ bersifat racun bagi tanaman maka diperlukan proses detoksifikasi di dalam tanaman sendiri. Proses ini terjadi dengan reaksi enzimatik $\mathrm{CN}$ dengan L-sistein membentuk $\beta$-cyanoalanine. Enzim yang dideteksi terlibat dalam proses ini adalah $\beta$-cyanoalanine synthase. $\beta$-cyanoalanine kemudian terhidrolisis menjadi asparagin sebagai bentuk yang tidak toksik (Larsen, 2005). Keberadaan enzim ini di dalam tanaman berkisar 3,9 hingga $1050 \mathrm{~nm}^{-1} \mathrm{~g}^{-1} \mathrm{mnt}^{-1}$. Kapasitas metabolisme $\mathrm{CN}$ juga bervariasi antara 6 - $1638 \mathrm{~kg}^{-1} \mathrm{jam}^{-1} \mathrm{CN}$, tergantung pada jenis tanaman dan umur jaringan tanaman. Tingkat metabolisme relatif besar pada jaringan tanaman yang lebih tua pada daerah yang masih memiliki aktivitas meristematik. (Larsen, 2005; Yu et al., 2005a).

Fitoekstraksi CN banyak dilakukan dengan menggunakan tanaman sianogenik, yaitu spesies tanaman yang dapat mensintesis glukosida sianogenik yang berfungsi dalam mendekomposisi $\mathrm{CN}$ bila jaringan tanaman terluka (Banks dan Mannering, 2006).Tanaman berpembuluh terbukti memiliki enzim yang dapat mendetoksifikasi $\mathrm{CN}$ dengan cara mengkonversinya ke asam amino asparagin (Larsen, 2005; Yu et al., 2005a). Tanaman yang dikenal sebagai akumulator CN adalah Salix viminalis yang memiliki laju removal untuk daun dan akar masing-masing sebesar 7 dan $9,5 \mathrm{mg} \mathrm{kg}{ }^{-1} \mathrm{~h}^{-1} \mathrm{CN}$. Adanya metabolisme CN dalam tanaman diindikasikan oleh hilangnya CN dari sistem medium-tanaman hingga 50\%-80\% (Larsen, 2005).

Saccharum spontaeum adalah tumbuhan dari golongan rumput-rumputan (Poaceae), dikenal dengan nama manjah. Rumput liar ini sangat kuat perakarannya, batangnya beruas dengan tinggi sampai $2 \mathrm{~m}$, tumbuh berkelompok. Daunnya berbentuk pita sepanjang $75-150 \mathrm{~cm}$. Perbungaan berbentuk malai, tangkainya berambut halus panjang dengan bulir bewarna putih atau ungu. Tanaman ini biasa tumbuh di tempat terbuka, tepi sungai, hutan dan semak belukar.

Saccharum spontaneum digunakan dalam penelitian ini karena termasuk salah satu jenis yang tumbuh dominan di lingkungan pembuangan limbah pengolahan emas (tailing dam) di Pongkor dan Cikotok (Sambas, 2003) Hasil skrining menunjukkan bahwa, pada limbah tailing Sacharum spontaneum menyerap hingga $10,25 \mathrm{mg} \mathrm{kg}^{-1} \mathrm{CN}$ dan termasuk pada kategori tumbuhan penyerap polutan dengan produksi biomassa yang tinggi. Karakteristik ini menjadikan $S$. spontaneum sebagai tanaman yang berpotensi sebagai akumulator untuk fitoremediasi lingkungan tercemar CN (Hidayati et al., 2006b). Medium terkontaminasi timbal (Pb) hingga 300 ppm dan tetap memproduksi biomassa secara normal tanpa menunjukkan gejala keracunan serta mampu mengakumulasi $\mathrm{Pb}$ hingga $45.7 \mathrm{ppm}$ pada tingkat $\mathrm{Pb} 300$ ppm dengan aplikasi kelat EDTA (Ethylenediaminetetracetic Acid) (Hidayati et al., 2006a).

Strategi fitoremediasi dalam meningkatkan ketersediaan, mobilitas logam pencemar dalam tanah, dan kapasitas akumulasi logam, dapat ditempuh salah satunya dengan aplikasi pupuk organik. Zn dan Cd pada tanaman yang diberi pupuk organik meningkat 3 - 10 kali dibanding kontrol (Baker et al., 1994; Chaney et al., 1995). Setiap unsur logam memiliki respon yang berbeda terhadap perlakuan $\mathrm{pH}$ maupun pupuk (Chaney et al., 1998).

Penelitian ini bertujuan mempelajari potensi Saccharum spontaneun dalam mengakumulasi $\mathrm{CN}$ dan efektivitas pupuk organik dalam meningkatkan produksi biomassa dan akumulasi CN pada tanaman karena tingkat akumulasi $\mathrm{CN}$ dalam tanaman merupakan fungsi dari total produksi biomassa dan konsentrasinya dalam tanaman (Wise et al., 2000). 


\section{Metode Penelitian}

Karakteristik tanah limbah tailing yang digunakan sebagai medium dalam penelitian ini adalah memiliki kualitas fisik dan kimia yang rendah, mengandung logam berat, termasuk timbal $(\mathrm{Pb})$, seng $(\mathrm{Zn})$, kadmium $(\mathrm{Cd})$, zat besi (Fe) dan sianida (CN) yang tinggi. Limbah PT ANTAM mengandung $\mathrm{Pb} 20$ kali; Fe 50 kali; Cd 40 kali dan Zn 2 kali lebih tinggi dibandingkan tanah non limbah. Disamping itu tanah limbah mengandung bahan organik dan KTK (Kapasitas Tukar Kation) yang rendah (2.36-5.18 cmol/kg) sehingga tidak favourable untuk pertumbuhan tanaman (Hidayati dan Saefudin, 2005).

Penelitian ex-situ ini dilakukan di rumah kaca Laboratorium Treub, Pusat Penelitian Biologi LIPI Bogor dengan kondisi rata-rata suhu udara $\pm 30^{\circ} \mathrm{C}$ dan kelembaban $\pm 88 \%$. Medium limbah tailing dan bahan hidup tanaman Saccharum spontaneum untuk penelitian dikoleksi dari lokasi pembuangan limbah penambangan emas, tailing dam milik PT. ANEKA TAMBANG Cikotok.

Dalam penelitian ini Saccharum spontaneum ditanam dalam pot dengan medium limbah tailing. Rumpun/anakan tanaman yang telah dipangkas daunnya hingga tersisa batangnya setinggi sekitar $30 \mathrm{~cm}$, ditanam satu rumpun dalam satu pot dan dibiarkan tumbuh hingga tumbuh 4-5 helai daun baru (sekitar umur 45 hari). Pada umur tersebut perlakuan penambahan CN diberikan dengan tingkat $0 \mathrm{mg} \mathrm{kg}{ }^{-1}$ (Cno), $5 \mathrm{mg} \mathrm{kg}$ (Cn1) dan $10 \mathrm{mg} \mathrm{kg}^{-1}$ (Cn2). Aplikasi pupuk organik diberikan sebelum tanam dengan perbandingan $1: 1$ berupa pupuk kandang (P1), kompos (P2) dan tanpa pupuk (Po) sebagai pembanding Percobaan dirancang secara acak kelompok faktorial dengan lima ulangan.

Parameter yang diamati meliputi pertumbuhan tanaman dan produksi biomassa serta tingkat akumulasi CN pada jaringan tajuk dan akar tanaman dan kandungan $\mathrm{CN}$ pada medium pada waktu panen yang berbeda untuk mengetahui waktu panen yang optimum dalam kaitannya dengan tingkat akumulasi $\mathrm{CN}$ dan untuk mengetahui kondisi CN dalam sistem (medium dan tanaman) agar dapat diketahui ada tidaknya $\mathrm{CN}$ yang berkurang dari sistem.

Analisis CN dilakukan di laboratorium Balai Besar Industri Agro, Bogor dengan metoda spektrofotometri.

\section{Hasil dan Pembahasan}

\section{Pertumbuhan tanaman}

Tidak terjadi hambatan pada pertumbuhan tanaman setelah perlakuan CN diberikan (umur 45 hari). Hal ini dibuktikan oleh penambahan tinggi tanaman dan jumlah anakan yang terus bertambah setelah perlakuan CN (Gambar 1 dan Gambar 2). Walaupun tingkat $\mathrm{CN}$ yang diberikan jauh lebih tinggi dari tingkat CN di habitat asal tanaman tetapi tanaman masih dapat bertahan dan menunjukkan pertumbuhan yang normal tanpa menunjukkan adanya gejala keracunan, terutama pada tingkat $\mathrm{CN}$ rendah (Cn1). Hal ini memberikan harapan bagi tanaman ini sebagai kandidat tanaman hiperakumulator untuk membersihkan pencemar $\mathrm{CN}$.

Pemberian pupuk organik berpengaruh pada penambahan jumlah anakan dan tinggi tanaman (Gambar 1 dan Gambar 2), serta mengakibatkan peningkatan produksi biomassa tanaman (Gambar 3 dan Gambar 4). Terdapat perbedaan produksi biomassa tajuk yang signifikan antara tanaman yang diberi pupuk dan tanaman kontrol. Demikian pula terdapat perbedaan produksi biomassa (tajuk dan akar) antara tanaman yang diberi pupuk kandang (P1) dan kompos (P2). Tanaman yang diberi perlakuan P1 menunjukkan produksi biomassa lebih tinggi dibandingkan tanaman yang diberi perlakuan P2 (Gambar 5 dan Gambar 6).

\section{Kandungan CN dan umur panen}

Pengaruh positif pemberian pupuk
organik terhadap produksi biomassa,
diharapkan memberikan pengaruh positif
terhadap serapan CN pada tanaman karena total
CN yang terakumulasi dalam tanaman
merupakan fungsi dari konsentrasi CN dan total
biomassa.




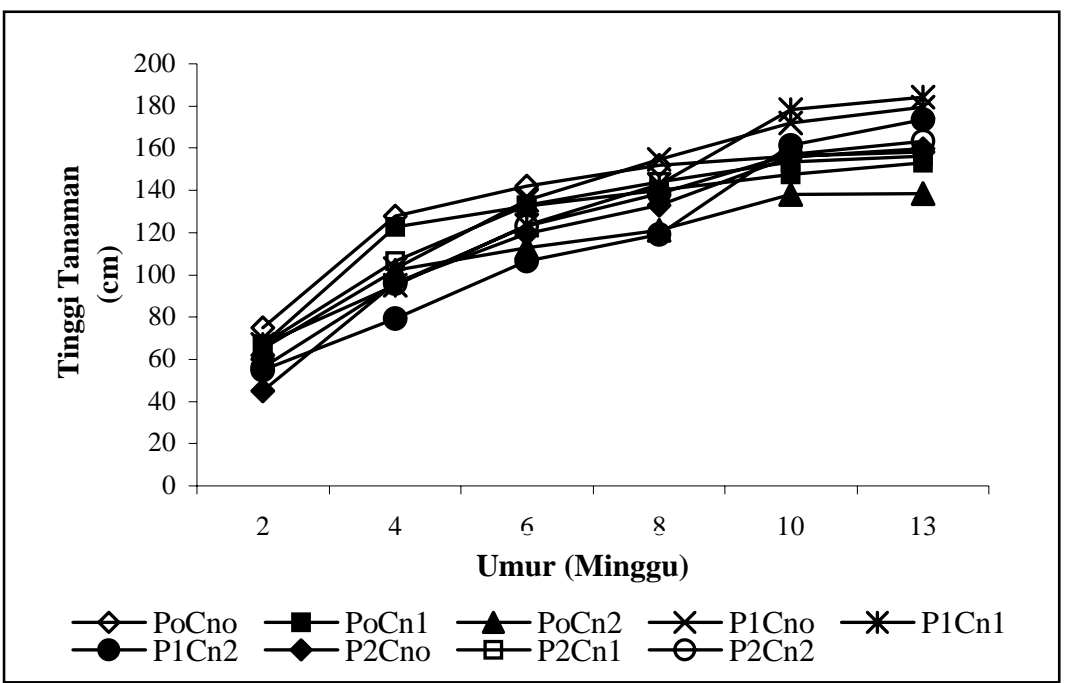

Gambar 1. Tinggi tanaman pada berbagai perlakuan $\mathrm{CN}$ dan pupuk organik



Gambar 2. Jumlah anakan pada berbagai perlakuan CN dan pupuk organik

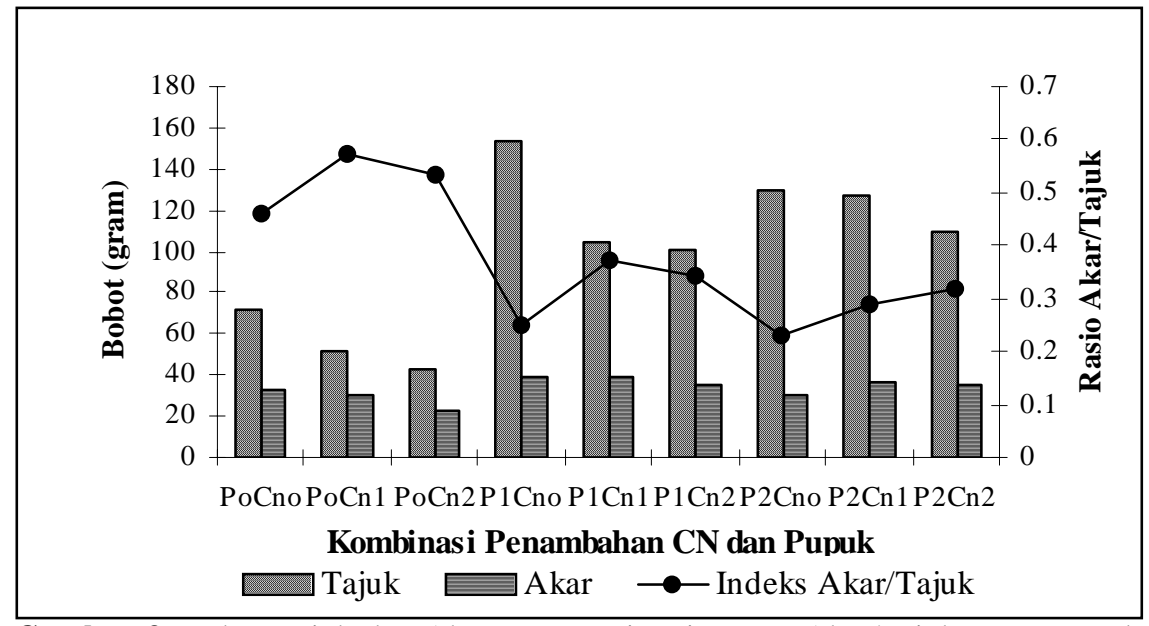

Gambar 3. Bobot Tajuk dan Akar serta Rasio Biomassa Akar/Tajuk Panen I pada berbagai Perlakuan CN dan pupuk Organik

Keterangan: Po:tanpa pupuk, P1: pupuk kandang, P2: pupuk kompos, Cno: tanpa penambahan CN, Cn1: CN 5 mg kg-1, Cn2: CN $10 \mathrm{mg} \mathrm{kg}^{-1}$ 


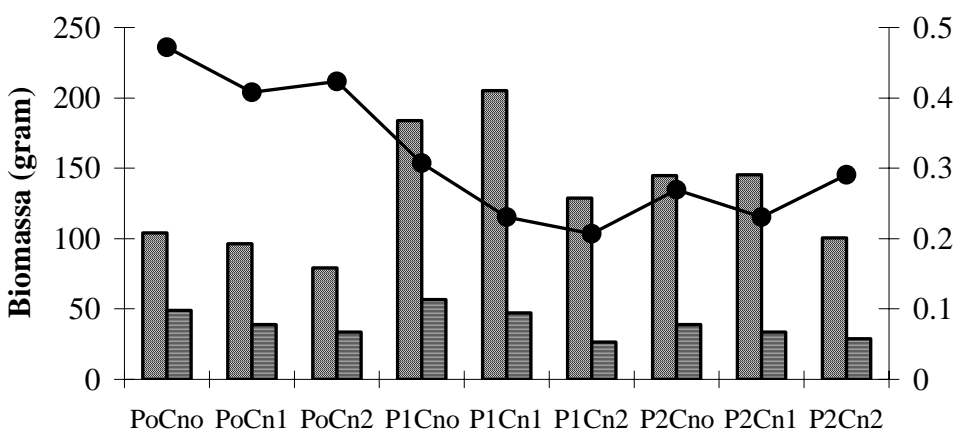

Kombinasi Penambahan CN dan Pupuk

$\square$ Tajuk $\square$ Akar $\longrightarrow$-Indeks Akar/Tajuk

Gambar 4. Bobot tajuk dan akar serta rasio biomassa akar/tajuk panen II pada berbagai perlakuan $\mathrm{CN}$ dan pupuk organik



Gambar 5. Produksi biomassa tajuk pada berbagai perlakuan CN dan pupuk organik

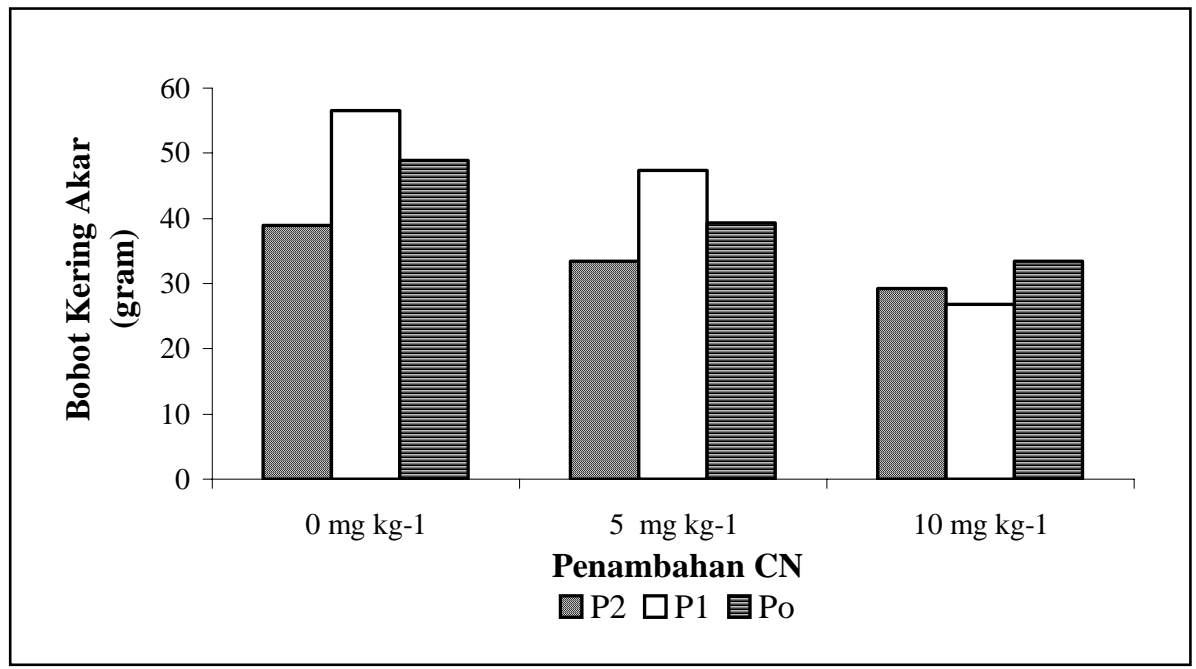

Gambar 6. Produksi biomassa akar pada berbagai perlakuan CN dan pupuk organik Keterangan: Po: tanpa pupuk, P1: pupuk kandang, P2: pupuk kompos 
Potensi Saccharum spontaneum sebagai tumbuhan toleran $\mathrm{CN}$ berpeluang untuk dapat ditingkatkan menjadi tumbuhan akumulator CN. Sebagai tumbuhan hipertoleran ditunjukkan oleh tanaman ini, yaitu dengan kemampuan pertumbuhan dan produksi biomassanya yang tidak jauh berbeda dengan tanaman kontrol pada medium tailing yang ditambah CN hingga $5 \mathrm{mg} \mathrm{kg}^{-1}$ (Gambar 5). Walaupun demikian ada kecenderungan semakin tinggi tingkat $\mathrm{CN}$ yang ditambahkan semakin menurun produksi biomassa tanaman (terutama akar). Hal ini terjadi baik pada tanaman yang diberi pupuk maupun tanaman yang tidak diberi pupuk (Gambar 5 dan Gambar 6). Ada kecenderungan bahwa pertumbuhan tanaman terhambat pada tingkat penambahan $10 \mathrm{mg} \mathrm{kg}{ }^{-1} \mathrm{CN}$ karena itu pada tingkat perlakuan ini diperoleh produksi biomassa tanaman yang paling rendah dibandingkan tingkat CN $5 \mathrm{mg} \mathrm{kg}^{-1}$ (Cn1) dan tanaman yang tidak diberi tambahan CN (Cno). Penurunan produksi biomassa ini lebih jelas terlihat pada akar yang menurun secara proporsional dengan meningkatnya kadar penambahan CN (Gambar 6), dibandingkan pengaruh CN pada produksi biomassa tajuk (Gambar 5).

Umur panen yang tepat diperlukan untuk memperoleh hasil optimum pada praktek fitoremediasi. Titik optimum ini ditujukan pada produksi biomassa tanaman dan yang utama pada tingkat akumulasi kontaminan yang paling tinggi, dalam hal ini tingkat konsentrasi CN pada tajuk. Dalam penelitian ini panen dilakukan dua tahap yakni pada saat tanaman umur 12 minggu dan 16 minggu. Setelah panen I (umur 12 minggu) tanaman masih mengalami penambahan biomassa, terutama tajuk, sehingga produksi biomassa pada panen II lebih tinggi dari panen I. Hal ini menunjukkan bahwa umur panen 12 minggu bukan merupakan umur panen yang optimum (Tabel 1 dan Tabel 2).

Tabel 1. Perbedaan produksi biomassa tajuk pada panen I dan II

\begin{tabular}{ccccc}
\hline \hline Perlakuan & Panen I & \multicolumn{2}{c}{ Bobot Basah Tajuk (gram) saat panen } & $\begin{array}{c}\text { Selisih Panen II-Panen I } \\
\text { (gram) }\end{array}$ \\
\cline { 3 - 4 } & & Panen II & Total & 31.60 \\
\hline \hline PoCno & 72.20 & 103.80 & 176.00 & 44.77 \\
PoCn1 & 51.58 & 96.35 & 147.93 & 36.90 \\
PoCn2 & 42.25 & 79.15 & 121.40 & 30.00 \\
P1Cno & 154.05 & 184.05 & 338.10 & 100.15 \\
P1Cn1 & 104.65 & 204.80 & 309.45 & 28.10 \\
P1Cn2 & 101.00 & 129.10 & 230.10 & 15.55 \\
P2Cno & 129.25 & 144.80 & 274.05 & 17.51 \\
P2Cn1 & 127.75 & 145.26 & 273.01 & -9.40 \\
P2Cn2 & 110.00 & 100.60 & 210.60 & \\
\hline \hline
\end{tabular}

Tabel 2. Perbedaan produksi biomassa akar pada panen I dan II

\begin{tabular}{ccccc}
\hline \hline Perlakuan & Panen I & \multicolumn{2}{c}{ Bobot Basah Akar (gram) saat panen } & $\begin{array}{c}\text { Selisih Panen II-Panen I } \\
\text { (gram) }\end{array}$ \\
\cline { 2 - 4 } & & Panen II & Total & 15.60 \\
PoCno & 33.30 & 48.90 & 82.20 & 9.70 \\
PoCn1 & 29.60 & 39.30 & 68.90 & 10.95 \\
PoCn2 & 22.55 & 33.50 & 56.05 & 17.85 \\
P1Cno & 38.65 & 56.50 & 95.15 & 8.30 \\
P1Cn1 & 39.00 & 47.30 & 86.30 & -7.90 \\
P1Cn2 & 34.65 & 26.75 & 61.40 & 9.20 \\
P2Cno & 29.80 & 39.00 & 68.80 & -3.18 \\
P2Cn1 & 36.68 & 33.50 & 70.18 & -6.00 \\
P2Cn2 & 35.25 & 29.25 & 64.50 & \\
\hline \hline
\end{tabular}

Keterangan: Po: tanpa pupuk, P1: pupuk kandang, P2: pupuk kompos, Cno: tanpa penambahan CN, Cn1: CN 5 $\mathrm{mg} \mathrm{kg}^{-1}$, Cn2: CN $10 \mathrm{mg} \mathrm{kg}^{-1}$ 
Pada panen I (umur 12 minggu), akumulasi CN pada tanaman mencapai 19,49 $\mathrm{mg} \mathrm{kg}^{-1}$ (total). Sebagian besar CN terakumulasi pada tajuk. Hal ini ditunjukkan oleh nilai rasio akumulasi tajuk/akar yang tinggi, yakni mencapai 7,95 (P1Cn1) (Tabel 3). Rasio akumulasi CN pada tajuk/akar yang tinggi merupakan salah satu karakter yang diharapkan pada tanaman hiperakumulator karena hal ini menunjukkan bahwa lebih banyak CN yang terakumulasi pada tajuk sehingga lebih mudah dipanen dan dipindahkan dari dalam tanah dibandingkan logam yang terakumulasi pada akar.

Panen I masih menyisakan $\mathrm{CN}$ pada medium 0,54 - 4,36 $\mathrm{mg} \mathrm{kg}^{-1}$, dibandingkan sisa CN setelah panen II (umur 16 minggu), sebesar 0,38-0,98 $\mathrm{mg} \mathrm{kg}^{-1}$ (Tabel 3). Pada panen II (satu bulan setelah panen I) total akumulasi CN pada tanaman lebih rendah dari panen I, yakni 1,98 - 9,9 $\mathrm{mg} \mathrm{kg}^{-1}$. Pada beberapa perlakuan perbedaan kandungan $\mathrm{CN}$ dari panen I dan panen II ini cukup tinggi mencapai 7,95 mg $\mathrm{kg}^{1}(\mathrm{P} 1 \mathrm{Cn} 1)$. Hal ini membuktikan bahwa panen I (umur 12 minggu) merupakan waktu yang optimum untuk tingkat akumulasi CN dalam tanaman (Tabel 3).

Pupuk organik tidak memberikan pengaruh yang nyata terhadap akumulasi CN dalam tanaman (Gambar 7 dan Gambar 8). Kandungan $\mathrm{CN}$ yang tinggi pada tanaman kemungkinan karena adanya $\mathrm{CN}$ yang terbawa dari lokasi yang terkontaminasi. Tanaman yang digunakan dalam penelitian ini adalah tanaman yang langsung dikoleksi dari lokasi yang tercemar CN dan dari hasil skrining kandungan CN pada Saccharum spontaneum dari lokasi tersebut mencapai $10 \mathrm{mg} \mathrm{kg}^{-1}$ (Hidayati et al., 2006b).

Total konsentrasi CN pada panen II lebih kecil dari total konsentrasi $\mathrm{CN}$ pada panen I. Hal ini dimungkinkan karena perbedaan metabolisme CN (Larsen dan Trapp, 2004; Larsen, 2005). Oleh karena CN bersifat racun bagi tanaman maka perlu bagi tanaman untuk mendetoksifikasi melalui reaksi enzimatik CN L-sistein membentuk $\beta$-cyanoalanine. Enzim yang dideteksi terlibat adalah $\beta$-cyanoalanine synthase. $\beta$-cyanoalanine kemudian terhidrolisis menjadi asparagin sebagai bentuk yang tidak toksik (Larsen, 2005). Keberadaan enzim ini di dalam tanaman berkisar 3.9 hingga $1050 \mathrm{~nm}^{-1} \mathrm{~g}^{-}$ ${ }^{1} \mathrm{mnt}^{-1}$. Kapasitas metabolisme $\mathrm{CN}$ juga bervariasi antara $6-1638 \mathrm{~kg}^{-1} \mathrm{jam}^{-1} \mathrm{CN}$ tergantung pada jenis tanaman dan umur jaringan tanaman. Tingkat metabolisme lebih besar pada jaringan tanaman yang lebih tua pada daerah yang masih memiliki aktivitas meristematik. (Larsen, 2005; Yu et al., 2005a). Adanya metabolisme $\mathrm{CN}$ dalam tanaman diindikasikan oleh hilangnya $\mathrm{CN}$ dari sistem medium-tanaman hingga 50\%-80\% (Larsen, 2005).

Tabel 3. Akumulasi sianida pada tajuk dan akar tanaman dan sianida pada medium dengan berbagai perlakuan tingkat konsentrasi sianida dan pupuk organik pada panen I dan II

\begin{tabular}{|c|c|c|c|c|c|c|c|c|c|c|c|}
\hline \multirow{2}{*}{ Perlakuan } & \multicolumn{5}{|c|}{ Panen I (Umur 12 Minggu) (mg kg ${ }^{-1}$ ) } & \multicolumn{5}{|c|}{ Panen II (Umur 16 Minggu) (mg kg ${ }^{-1}$ ) } & \multirow[b]{2}{*}{$\begin{array}{l}\text {-Total CN Panen I- } \\
\text { Panen II }\end{array}$} \\
\hline & Medium & Akar & Tajuk & Total & $\begin{array}{c}\text { Rasio } \\
\text { Tajuk/Akar } \\
\end{array}$ & $\begin{array}{l}\text { Mediu } \\
\text { m }\end{array}$ & Akar & Tajuk & Total & $\begin{array}{c}\text { Rasio } \\
\text { Tajuk/Akar } \\
\end{array}$ & \\
\hline PoCno & 0,54 & 3,05 & $7,7,30$ & 10,35 & 2,39 & 0,38 & 0,40 & 4,75 & 5,15 & 11,88 & 5,20 \\
\hline PoCn1 & 3,56 & 5,02 & 5,81 & 10,83 & 1,16 & 0,90 & 1,98 & 2,78 & 4,76 & 1,40 & 6,07 \\
\hline PoCn2 & 4,36 & 7,29 & 7,93 & 15,22 & 1,09 & 0,87 & 3,17 & 0,79 & 3,96 & 0,25 & 11,26 \\
\hline P1Cno & 2,38 & 16,81 & 2,68 & 19,49 & 0,16 & 0,48 & 4,36 & 2,78 & 7,14 & 0,68 & 12,35 \\
\hline P1Cn1 & 1,19 & 0,58 & 4,61 & 5,19 & 7,95 & 0,56 & 2,78 & 2,38 & 5,16 & 0,86 & 0,03 \\
\hline P1Cn2 & 0,79 & 2,97 & 10,43 & 13,40 & 3,51 & 0,98 & 0,40 & 2,38 & 2,78 & 5,95 & 10,62 \\
\hline P2Cno & 3,17 & 2,98 & 3,05 & 6,03 & 1,02 & 0,81 & 5,54 & 4,36 & 9,90 & 0,79 & $-3,87$ \\
\hline P2Cn1 & 2,38 & 2,78 & 2,22 & 5,00 & 0,79 & 3,42 & 3,17 & 2,38 & 5,55 & 0,75 & $-0,55$ \\
\hline P2Cn2 & 3,17 & 2,45 & 2,74 & 5,19 & 1,12 & 0,84 & 0,79 & 1,19 & 1,98 & 1,51 & 3,21 \\
\hline
\end{tabular}

Keterangan: Po: tanpa pupuk, P1: pupuk kandang, P2: pupuk kompos, Cno: tanpa penambahan CN, Cn1: CN 5 $\mathrm{mg} \mathrm{kg}{ }^{-1}$, Cn2: CN $10 \mathrm{mg} \mathrm{kg}$. Kandungan CN pada medium sebelum perlakuan: $0.77 \mathrm{mg} \mathrm{kg}^{-1}$ 


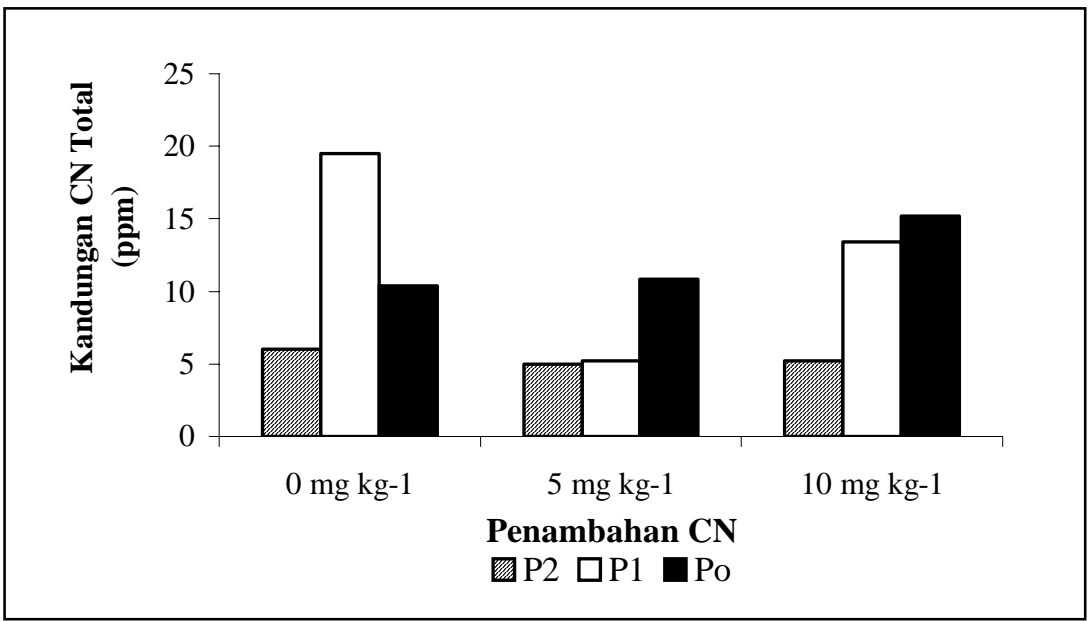

Gambar 7. Kandungan CN total pada perlakuan CN dan pupuk pada panen I

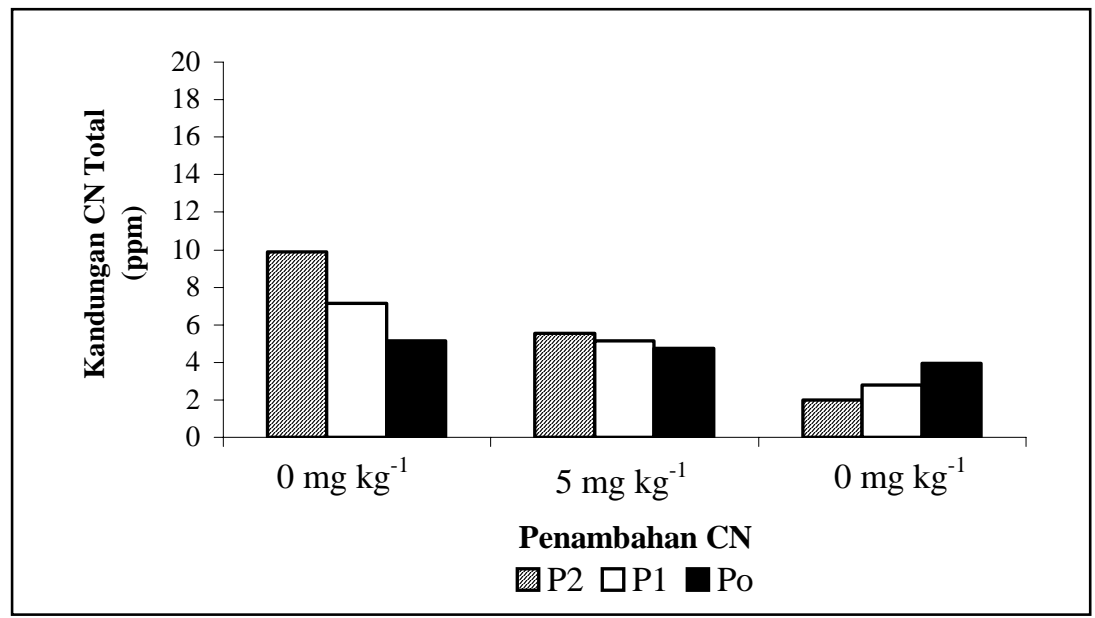

Gambar 8. Kandungan CN total pada perlakuan CN dan pupuk pada panen II

Keterangan: Po: tanpa pupuk, P1: pupuk kandang, P2: pupuk kompos

Akumulasi CN hanya dideteksi pada tingkat kontaminasi $\mathrm{CN}$ yang sangat tinggi pada level yang toksik. Fitotoksisitas CN berpengaruh terhadap transpirasi yang menurun hingga 50\% pada konsentrasi CN dalam larutan 2 - $8 \mathrm{mg} / \mathrm{l}$ bergantung lamanya perlakuan. Pada konsentrasi lebih tinggi toksisitas berakibat pada kematian tanaman (Larsen dan Trapp, 2004; Larsen, 2005; Yu et al., 2005b).

Pada tumbuhan hiperakumulator disamping diharapkan rasio biomassa akar/tajuk yang proporsional, juga rasio konsentrasi logam pada tajuk/akar lebih dari 1. Hal ini mengindikasikan sistem translokasi logam dari akar ke tajuk yang efisien (Salt, 2000).

Banyak faktor yang mempengaruhi daya akumulasi kontaminan dalam tanaman akumulator diantaranya adalah $\mathrm{pH}$ tanah. Parameter $\mathrm{pH}$ penting bagi penyerapan logam karena nilai $\mathrm{pH}$ tanah merupakan faktor utama dalam mengontrol ketersediaan logam di dalam tanah. Pada tanah dengan nilai $\mathrm{pH}$ kurang dari 5.6 terdapat lebih banyak logam yang tersedia dari pada pada $\mathrm{pH}$ lebih dari 5.6. Namun $\mathrm{pH}$ optimum untuk pertumbuhan tanaman adalah 5.0 - 8.0 maka perlu dicari tanaman pengakumulasi yang tahan $\mathrm{pH}$ tanah rendah agar tidak terhambat pertumbuhannya diantaranya adalah Saccharum spontaneum (Hong et al., 2006). 


\section{Kesimpulan}

Penelitian ini dapat disimpulkan bahwa Saccharum spontaneum terbukti berpotensi sebagai tanaman hiperakumulator CN. Pemupukan organik meningkatkan produksi biomassa tanaman tetapi tidak memberikan pengaruh nyata pada daya akumulasi CN tanaman. Umur panen 12 minggu merupakan waktu yang tepat untuk akumulasi CN.

\section{Daftar Pustaka}

Baker, A.J.M., Reeves, R.D. and Hajar, A.S.M. 1994. Heavy metal accumulation and tolerance in British populations of the metallophyte Thlaspi caerulescens J.\&C. Presl (Brassicaceae). New Phytol. 127: 61-68.

Banks, M.K. and Mannering, F. 2006. Phytoremediation of cyanide contaminated soils. http://www. hsrc.org/mw-cyanide.html. 09/30/2006.

Chaney, R.L., Brown, S.L., Li, Y.M., Angle, J.S., Homer, F. and Green, C. 1995. Potential use of metal hyperaccumulators. Mining Environ Management 3 (3): 9-11.

Chaney, R.L., Li, Y.M., Angle, J.S., Baker, A.J.M., Reeves, R.D., Brown, S.L., Homer, F.A., Malik, M. and Chin, M. 1998b. Improving metal hyperaccumulators wild plants to develop commercial phytoextraction system: Aproaches and progress. Di dalam: Proc Symp Phytoremediation, Inc Conf Biochemistry of Trace Elements. Berkeley, CA. In Press. 2326 Juni 1997.

Hidayati, N. dan Saefudin. 2005. Potensi Hipertoleransi dan Serapan Beberapa Jenis Tumbuhan pada Limbah Pengolahan Emas. J. Biol. Indonesia. III (9): 351- 359.

Hidayati, N., Juhaeti, T. dan Syarif, F. 2006a. Efektivitas EDTA (Ethylenediaminetetracetine Acid) Dalam Meningkatkan Akumulasi Timbal pada Saccharum spontaneum yang Tumbuh di Limbah Penambangan. J. Biol. Indonesia IV (1): 29-37.
Hidayati, N., Juhaeti, T. and Syarif, F. 2006b. Mercury and Cyanide Contamination in Aquatic Environments Around Two Gold Mine Areas and Possible Solution of Using Green Technology of Phytoremediation.International JSPS Seminar. Bogor.

Hong, P.K.A., Okey, R.W., Lin, S.W. and Chen, T.C. 2006. Structure-activity relationship of heavy metalls extraction from soil by chelating agents. http://www.engg.ksu.edu/HSRC/95 Proceed/hong.html.

Larsen, M. 2005. Plant uptake of cyanide. Ph.D. Thesis. Institute of Environment \& Resources. Technical University of Denmark. 37p.

Larsen, M. and Trapp, S. 2004. Remoal of cyanide by woody plants. Chemosphere 54 (3): 325-333.

Salt, D.E. 2000. Phytoextraction: Present applications and future promise. In: Wise, D.L., Trantolo, D.J., Cichon, E.J., Inyang, H.I. and Stottmeister, U. (Eds.). Bioremediation of Cotaminated Soils. pp. 729-743 Marcek Dekker Inc. New York; Basel.

Sambas, E.N. 2003. Analisis Vegetasi Tumbuhan Bawah pada Areal Tailing Dam PT Aneka Tambang (Antam) Pongkor. Laporan Teknik. Pusat Penelitian Biologi LIPI Bogor.

Wise, D.L., Trantolo, D.J., Cichon, E.J., Inyang, H.I. and Stottmeister, U. (Eds.). 2000. Bioremediation of Cotaminated Soils. Marcek Dekker Inc. New York; Basel.

Yu, X., Zhou, P., Zhou, X. and Liu, Y. 2005a. Cyanide removal by Chinese vegetation-quantification of the Michaelis-Menten kinetics. Environ.Sci.Pollut.Res.Int. 12 (4): 221-226.

Yu, X., Trapp, S. and Zhou, P. 2005b. Phytotoxicity of cyanide to weeping willow trees. Sci.J.Com. http://dx.doi.org/10.1065/espr 2005.02.237. 